\title{
High Constitutive Cytokine Release by Primary Human Acute Myeloid Leukemia Cells Is Associated with a Specific Intercellular Communication Phenotype
}

\author{
Håkon Reikvam ${ }^{1,2, *}{ }^{(0}$, Elise Aasebø ${ }^{1}\left(\mathbb{0}\right.$, Annette K. Brenner ${ }^{2}$, Sushma Bartaula-Brevik ${ }^{1}$, \\ Ida Sofie Grønningsæter ${ }^{2}$, Rakel Brendsdal Forthun ${ }^{2}$, Randi Hovland 3,4 \\ and Øystein Bruserud 1,2 \\ 1 Department of Clinical Science, University of Bergen, 5020,Bergen, Norway \\ Department of Medicine, Haukeland University Hospital, 5021 Bergen, Norway \\ Department of Medical Genetics, Haukeland University Hospital, 5021 Bergen, Norway \\ 4 Institute of Biomedicine, University of Bergen, 5020 Bergen, Norway \\ * Correspondence: Hakon.Reikvam@med.uib.no; Tel.: +55-97-50-00
}

Received: 23 May 2019; Accepted: 1 July 2019; Published: 4 July 2019

check for updates

\begin{abstract}
Acute myeloid leukemia (AML) is a heterogeneous disease, and this heterogeneity includes the capacity of constitutive release of extracellular soluble mediators by AML cells. We investigated whether this capacity is associated with molecular genetic abnormalities, and we compared the proteomic profiles of AML cells with high and low release. AML cells were derived from 71 consecutive patients that showed an expected frequency of cytogenetic and molecular genetic abnormalities. The constitutive extracellular release of 34 soluble mediators (CCL and CXCL chemokines, interleukins, proteases, and protease regulators) was investigated for an unselected subset of 62 patients, and they could be classified into high/intermediate/low release subsets based on their general capacity of constitutive secretion. FLT3-ITD was more frequent among patients with high constitutive mediator release, but our present study showed no additional associations between the capacity of constitutive release and 53 other molecular genetic abnormalities. We compared the proteomic profiles of two contrasting patient subsets showing either generally high or low constitutive release. A network analysis among cells with high release levels demonstrated high expression of intracellular proteins interacting with integrins, RAC1, and SYK signaling. In contrast, cells with low release showed high expression of several transcriptional regulators. We conclude that AML cell capacity of constitutive mediator release is characterized by different expression of potential intracellular therapeutic targets.
\end{abstract}

Keywords: acute myeloid leukemia; gene mutations; differentiation; cytokines; proteomic profile; integrin; RAC1; SYK

\section{Introduction}

Acute myeloid leukemia (AML) is a heterogeneous hematological malignancy characterized by clonal proliferation of a hierarchically organized leukemia cell population that arises from hematopoietic progenitors in the bone marrow [1-3]. AML is distinguished from other related blood disorders by the presence of at least $20 \%$ myeloblasts in the bone marrow [1-3]. However, despite this common characteristic, AML is very heterogeneous [1], and patients differ, for example, with regard to genetic abnormalities [4-7], transcriptional [8] and cell cycle regulation [9], autocrine and paracrine growth regulation [10-13], as well as the cellular metabolomic [14] and proteomic profiles [15-17]. This cell population heterogeneity is also reflected in the biological characteristics of AML stem cells $[8,10]$. 
Most relapses occur within 2-3 years after diagnosis and the overall five-year leukemia-free survival for younger AML patients able to receive intensive chemotherapy possibly combined with stem cell transplantation is only $45-50 \%$, and a major cause of death is chemoresistant AML relapse thought to originate from remaining AML or preleukemic cells that recapitulate disease development [18-21]. Cure is not possible for the large group of elderly/unfit patients who cannot receive such intensive therapy due to an unacceptable high risk of severe treatment-related morbidity or treatment-related mortality [2]. Thus, there is a need for identification of new therapeutic targets and development of new therapeutic strategies that are more efficient and better tolerated [22]. Targeting of the bidirectional communication between AML cells and their neighboring leukemia-supporting stromal cells is a possible approach [23-28]. In a previous study investigating another patient cohort, we described that high constitutive mediator release is associated with better long-term overall survival compared with low constitutive release [29]. The aims of the present study were, therefore, to characterize the in vitro secretome of primary human AML cells, to investigate possible associations between the capacity of constitutive mediator secretion and molecular genetic abnormalities, and to compare the proteomic profiles for primary AML cells with generally high and low capacity of releasing extracellular soluble mediators.

\section{Materials and Methods}

\subsection{AML Patients and Preparation of Primary AML Cells}

The study was approved by the Regional Ethics Committee (REK) (REK III 060.02, 10th of June 2002; REK Vest 215.03, 12th of March 04; REK III 231.06, 15th of March 2007; REK Vest 2013/634, 19th of March 2013; REK Vest 2015/1410, 19th of June 2015), The Norwegian Data Protection Authority 02/1118-5, 22 October 2002, and The Norwegian Ministry of Health 03/05340 HRA/ASD, 16 February 2004. All samples were collected after written informed consent.

The study population included 71 consecutive AML patients with high peripheral blood blast counts $\left(>5 \times 10^{9} / \mathrm{L}\right)$ and a high percentage of leukemic blasts among peripheral blood leukocytes (Table 1). Highly enriched AML cell populations (at least 95\% leukemic blasts) could thereby be prepared by density gradient separation alone (Lymphoprep, Axis-Shield, Oslo, Norway). The cells were stored in liquid nitrogen until used in the experiments [30].

Table 1. The clinical and biological characteristics of the 71 acute myeloid leukemia (AML) patients included in the study.

\begin{tabular}{cccc}
\hline \multicolumn{2}{c}{ Age and gender } & Etiology \\
\hline Median (years) & 64 & Previous chemo-radiotherapy & 1 \\
Range (years) & $18-90$ & CML & 1 \\
Females & 31 & Li-Fraumeni's syndrome & 1 \\
Males & 40 & Polycythemia vera & 1 \\
& & MDS & 8 \\
& Relapse & 10 \\
& & de novo & 49 \\
\hline FAB $^{1}$ classification & Cytogenetic abnormalities ${ }^{3}$ & \\
M0/1 & 26 & Adverse & 17 \\
M2 & 14 & Favorable & 5 \\
M4/5 & 22 & Intermediate & 43 \\
M6 & 1 & Normal & $40^{4}$ \\
Unknown & 8 & Unknown & 6 \\
\hline & & CD34 expression & \\
\hline Negative $(<20 \%)$ & $28^{2}$ & & \\
Positive $(>20 \%)$ & 43 &
\end{tabular}

${ }^{1}$ The French-American-British classification. ${ }^{2}$ The percentage of positive cells in flow cytometric analysis. ${ }^{3}$ The European Leukemia Net classification was used [2]. ${ }^{4}$ The 43 patients classified as intermediate cytogenetics included 40 patients with normal karyotype. Abbreviations: CML, chronic myeloid leukemia; MDS, myelodysplastic syndrome. 


\subsection{Mutation Profiling, Flow Cytometric Analyses, and Analysis of Global Gene Expression Profiles}

Submicroscopic mutation profiling of 54 genes frequently mutated in AML was done by using the Illumina TruSight Myeloid Gene Panel and sequenced using the MiSeq system and reagent kit v3 (all from Illumina, San Diego, CA, USA). A detailed description of the methodology and the 54 genes is given in a previous publication [31]. Fragment analysis of FLT3 exon 14-15, NPM1 exon 12, and sequencing of CEBPA were performed as described previously [32].

Immunophenotyping was performed as a part of the standard diagnostic workup using freshly isolated cells [2], and analyses were performed by multiparametric flow cytometry (BD FACS Canto; Franklin Lakes, NJ, USA).

Our methods for analysis of global mRNA profiles have been described previously [31]. All these analyses were performed using the Illumina iScan Reader and based upon fluorescence detection of biotin-labeled cRNA. For each sample, $300 \mathrm{ng}$ of total RNA was reversely transcribed, amplified, and biotin-16-UTP-labeled (Illumina TotalPrep RNA Amplification Kit; Applied Biosystems/Ambion; San Diego, CA, USA). The amount and quality of the biotin-labeled cRNA was controlled by the NanoDrop spectrophotometer and Agilent 2100 Bioanalyzer (Agilent Technologies, Inc.; Santa Clara, CA, USA). Biotin-labeled cRNA (750 ng) was hybridized to the HumanHT-12 V4 Expression BeadChip. The Human HT-12 V4 BeadChip targets 47,231 probes that are mainly derived from genes in the NCBI RefSeq database (Release 38). Data from the array scanning were investigated in GenomeStudio and J-Express 2012. All arrays within each experiment were quantile normalized before being compiled into an expression profile data matrix.

\subsection{Analysis of Constitutive Mediator Release by Primary Human AML Cells}

The studies of constitutive mediator release included a consecutive subset of 46 patients from the original study population (see Section 2.1 and Table 1$)$. AML cells $\left(1 \times 10^{6} / \mathrm{mL}\right)$ were cultured for $48 \mathrm{~h}$ in Stem Span SFEM ${ }^{\mathrm{TM}}$ medium in flat-bottomed 24-well $(2 \mathrm{~mL} /$ well) culture plates (Nunc Micro-Well; Sigma-Aldrich, Saint-Louis, MO, USA) before supernatants were collected and stored at $-80{ }^{\circ} \mathrm{C}$ until analyzed. The levels of the following 34 mediators were determined by Luminex analyses (R\&DSystems; Minnesota, MN, USA) or enzyme-linked immunosorbent assays (ELISA) (R\&D Systems; Minnesota, MN, USA): (i) the chemokines CCL2-5 and CXCL1/2/5/8/10/11; (ii) the interleukins IL-1 $\beta / 1 R A / 6 / 10 / 33$; (iii) the matrix metalloproteinases MMP-1/2/9 together with the protease/protease regulators tissue inhibitor of metalloproteinases 1 (TIMP-1), Cystatin B and C, polymorphonuclear (PMN) elastase, serpin $\mathrm{C} 1$ and $\mathrm{E}$, and CD147, plasminogen activator (PA), and complement factor D (CFD); (iv) the immunomodulatory tumor necrosis factor- $\alpha$ (TNF); (v) the growth factors granulocyte-macrophage colony-stimulating factor (GM-CSF), hepatocyte growth factor (HGF), heparin-binding EGF-like growth factor (HB-EGF), basic fibroblast growth factor (bFGF), and vascular endothelial growth factor (VEGF); and (vi) the soluble angiopoietin-1 receptor tyrosine kinase with immunoglobulin-like and EGF-like domain 2 (Tie-2).

\subsection{Proteomic Profiling: Selection of Patients, Sample Preparation, and Proteomic Analysis}

The present study is based on mutational analysis of the leukemic cells for 71 consecutive and thereby unselected AML patients with a high number and/or percentage of AML blasts in the peripheral blood (Table 2). This selection based on the peripheral blood blast level (see Section 2.1) was used to reduce the risk of inducing molecular alterations in the leukemia cells due to more extensive separation procedures. The karyotyping (Table 1) as well as the mutational analyses showed an expected frequency of both cytogenetic and molecular genetic abnormalities, suggesting that despite the separation-dependent selection of patients, they are representative for AML in general. Constitutive cytokine release was investigated for a consecutive and thereby unselected subset of 46 patients from the original study population. Global proteomic profiling of enriched AML cells was performed for 16 of the 46 patients included in the constitutive release study; and these 16 patients represent 
all patients in the secretomic cohort completing intensive antileukemic treatment with induction chemotherapy followed by either $2-4$ consolidation cycles or allogeneic stem cell transplantation as the final consolidation. Thus, they represent an unselected subset of relatively young and fit patients (Tables S1,S2).

Table 2. An overview of the mutational landscape of 71 consecutive AML patients. The table presents the main classification and the number of mutations. For each main class the term total group refers to the total number of mutations in this class (first number) together with the number of patients with mutations belonging to this main class (second number). Those mutations that should be included as a part of the prognostic evaluation in routine clinical practice are marked with arrows ( $\uparrow$ increased survival; $\downarrow$ decreased survival) [2].

\begin{tabular}{|c|c|c|c|c|c|}
\hline Classification & Mutation & $\begin{array}{l}\text { Number with } \\
\text { Mutation }\end{array}$ & Classification & Mutation & $\begin{array}{c}\text { Number with } \\
\text { Mutation }\end{array}$ \\
\hline \multirow{2}{*}{ NPM1 } & 个NPM1 & 20 & \multirow{5}{*}{$\begin{array}{l}\text { Chromatin } \\
\text { modification }\end{array}$} & $\downarrow$ ASXL1 & 12 \\
\hline & Total group & $20-20$ & & EZH2 & 3 \\
\hline \multirow{9}{*}{ Signaling } & $\downarrow$ FLT3-ITD & 20 & & GATA2 & 4 \\
\hline & FLT3-TKD & 8 & & KDM6A & 1 \\
\hline & HRAS & 1 & & Total group & $20-15$ \\
\hline & JAK2 & 1 & \multirow{4}{*}{$\begin{array}{c}\text { Myeloid } \\
\text { transcription factors }\end{array}$} & & \\
\hline & KIT & 1 & & ^СЕВPA & 8 \\
\hline & KRAS & 5 & & $\downarrow R U N X 1$ & 13 \\
\hline & NRAS & 10 & & Total group & $21-18$ \\
\hline & PTPN11 & 3 & \multirow{6}{*}{$\begin{array}{l}\text { Spliceosome/ } \\
\text { transcription } \\
\text { repressors }\end{array}$} & BCOR & 4 \\
\hline & Total group & $49-42$ & & BCORL1 & 4 \\
\hline \multirow{7}{*}{$\begin{array}{c}\text { Tumor } \\
\text { suppressors }\end{array}$} & CDKN2A & 1 & & SF3B1 & 2 \\
\hline & CUX1 & 1 & & SRSF2 & 8 \\
\hline & IKZF1 & 7 & & ZRSB2 & 1 \\
\hline & PHF6 & 3 & & Total group & $19-15$ \\
\hline & TP53 $\downarrow$ & 7 & \multirow{4}{*}{ Cohesin } & RAD21 & 2 \\
\hline & WT1 & 5 & & SMC1A & 1 \\
\hline & Total group & $24-21$ & & STAG2 & 8 \\
\hline \multirow{6}{*}{$\begin{array}{c}\text { DNA } \\
\text { methylation }\end{array}$} & DNMT3A & 19 & & Total group & $11-11$ \\
\hline & IDH1 & 5 & \multirow{5}{*}{ Others } & CSF3R & 3 \\
\hline & IDH2 & 11 & & NOTCH1 & 2 \\
\hline & KMT2A/MLL & 2 & & SETBP1 & 1 \\
\hline & TET2 & 12 & & Total group & $6-5$ \\
\hline & Total group & $49-39$ & & & \\
\hline
\end{tabular}

We followed the step-by-step procedure published previously for proteomic sample preparation and analysis of primary AML cells [15], except for the following two modifications: the $20 \mu \mathrm{g}$ cell lysates were analyzed as label-free samples in contrast to being spiked with an internal standard, and no peptide fractionation was performed. The samples were analyzed on a QExactive HF Orbitrap mass spectrometer (Thermo Fisher Scientific; Waltham, MA, USA) coupled to an Ultimate 3000 Rapid Separation LC system (Thermo Fisher Scientific) [33,34]. The raw LC-MS files were searched against a concatenated reverse-decoy Swiss-Prot Homo sapiens fasta file (downloaded 05.03.18, containing 42,352 entries) in MaxQuant version 1.6.1.0 [35,36].

\subsection{Bioinformatical and Statistical Analyses and Presentation of the Data}

All statistical analyses were performed in GraphPad Prism 5 (GraphPad Software, Inc., San Diego, CA, USA). Unless otherwise stated, $p$-values $<0.05$ were regarded as statistically significant. The Fisher's Exact test was used to compare different groups (two-tailed $p$-values). Bioinformatical analyses were performed using the J-Express 2009 analysis suite (MolMine AS, Bergen, Norway) [37]. Concentrations were then median normalized and transformed to logarithmic values before differences were analyzed. Unsupervised hierarchical clustering was performed with Euclidian correlation and complete distance 
measure for all analyses in J-Express. The Panther classification system (version PANTHER14.0) was used to identify distinct functional classes [38].

The proteomics data processing of the raw data (i.e., filtering for reverse hits, contaminants and proteins only identified by site, and $\log _{2}$ transformation of label-free quantification (LFQ) intensities), and statistical analysis of two groups using Welch's $t$-test was performed in Perseus version 1.6.1.1. [39]. Furthermore, Z-statistics were used to find the proteins with the most abundant fold changes (FCs), i.e., the proteins with highest or lowest FC when comparing the high-release with the low-release group and calculating the FCs from the median $\log _{2}$ intensity per group as described by others [40]. Unsupervised hierarchical clustering was performed with Euclidian correlation and complete distance measure for all analyses in J-Express [37], and gene ontology analysis in DAVID version 6.8 [41]. Gene ontology (GO) terms with false discovery rate $(\mathrm{FDR})<0.05$, the number of proteins associated to the term, and the fold enrichment were presented. The significantly different proteins were imported to the STRING database version 11.0 [42] to obtain protein-protein interaction networks, using experiments and databases as interaction sources at highest confidence (0.9). The networks were imported and visualized in Cytoscape version 3.3.0 [43]. Venny 2.1 (http://bioinfogp.cnb.csic.es/tools/venny/) was used to create Venn diagrams.

To summarize, due to the previously described AML heterogeneity and the fact that we sometimes have unequal numbers of quantified values of a protein in the two groups, we assumed an unequal variation in the groups and first applied the Welch $t$-test to identify proteins with significantly $(p<0.05)$ different mean tests. Thereafter we used Z-statistics as an additional test to identify those proteins with the most extreme/significant fold changes (fold change defined as the median intensity for high-release patients relative to the median intensity for low-release patients; the intensities were then $\log 2$-transformed).

\section{Results}

3.1. The Genetic Heterogeneity of AML Patients: TP53 Mutations are Associated with High-Risk Karyotypes and NPM1 Mutations are Associated with Mutations in DNA Methylation Genes

We analyzed the submicroscopic mutational profile for all 71 patients. The profile included 54 frequent mutated genes in myeloid malignancies, 37 of them carried non-benign mutations in our patients (Figure 1). At least one mutation was detected for 69 of the 71 patients, and one of patients without detected mutations had a balanced translocation. The median number of mutations per patient was 3.5 (range $0-7$ ). The most frequently detected mutations were NPM1 exon 12 insertion and the FLT3-ITD mutation (20 patients for each), followed by mutations in the DNMT3A (19), TET2 (13), and RUNX1 (13) genes (Figure S1).

We used the same (and now generally accepted) classification of AML-associated mutations in our present study as was used in two large previous studies, including 1540 and 200 patients, respectively [6,7]. The following mutations were detected in our patients: (i) NPM1 insertion (detected in 20 out of the 71 patients), (ii) mutations causing activation of intracellular signaling (9 genes, 42 patients), (iii) mutated tumor suppressor genes (8 genes, 21 patients), (iv) mutations in genes involved in DNA methylation (5 genes, 39 patients) or (v) chromatin modification (3 genes, 15 patients), (vi) mutations in genes encoding myeloid transcription factors (3 genes, 20 patients), (vii) mutated genes important for the spliceosome (5 genes, 15 patients), (vii) mutated genes encoding cohesion proteins ( 3 genes, 9 patients), and (viii) the three genes CSF3R, NOTCH1, and SETBP1 that were mutated in 5 patients (Table 2). The median number of different class mutations per patient was 2.5 (range $0-5$ ); $24 \%$ of the patients had mutations from two different main classes and $34 \%$ from three main classes of mutations (Table S1). 


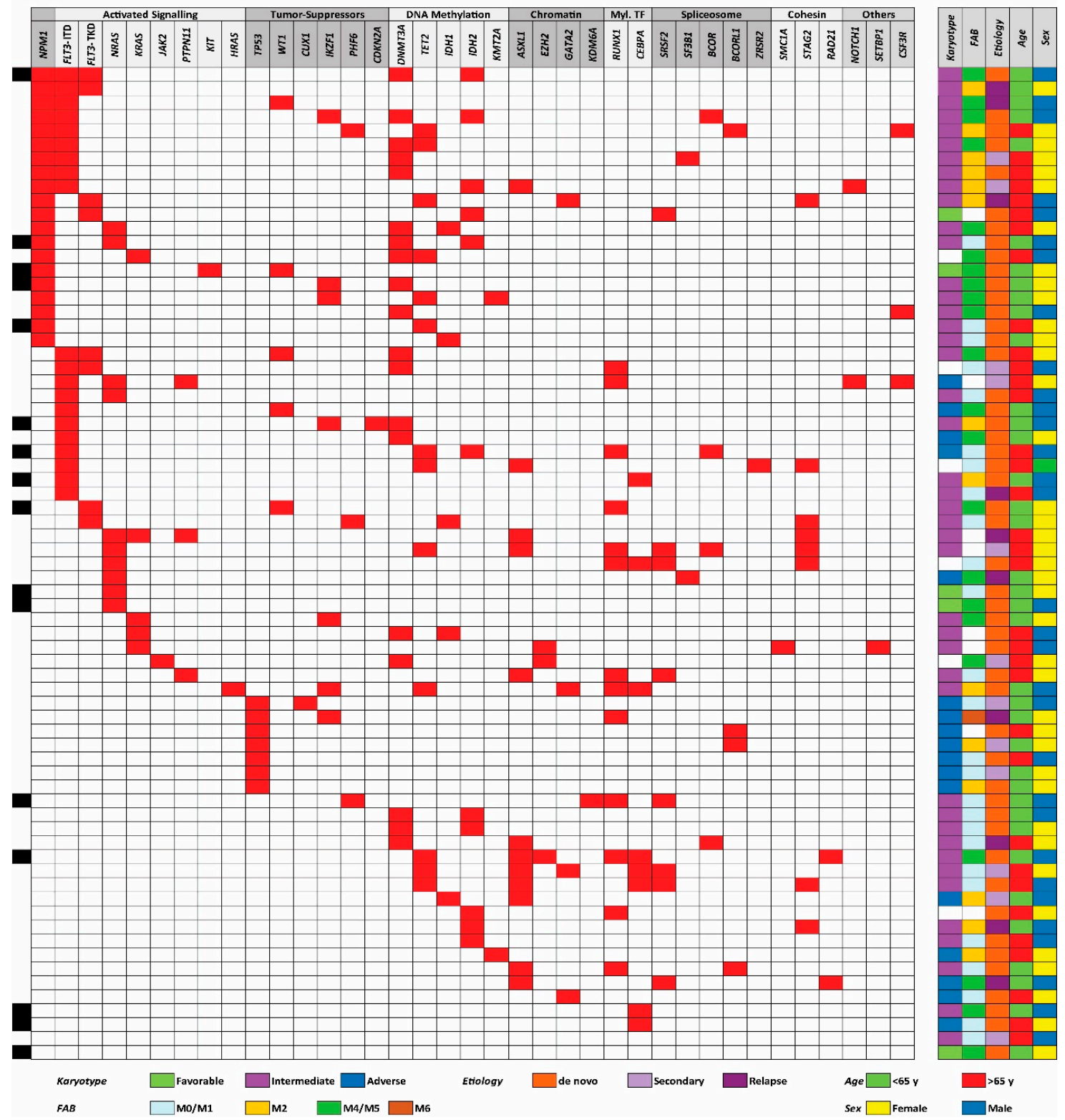

Figure 1. The total genomic profile and organization of mutations into defined categories; an overview of the data for the 71 AML patients included in our study. The figure shows the somatic mutations identified from a 54 gene mutation panel, the mutations being classified as described previously [6,7]. A majority of 69 patients had at least one detectable mutation. Risk classification of the karyotypes, morphological signs of differentiation (i.e., FAB-classification), etiology, age, and gender are presented in the right part of the figure. The patients selected for proteomic analyses are indexed with black in the left part of the figure.

We compared the mutational status with karyotype, French-American-British (FAB) classification (i.e., morphological differentiation), de novo versus secondary leukemia, age, and gender (Figure 1); these statistical analyses are summarized in Table S3. Firstly, we observed a highly significant association between NPM1 and DNA methylation gene mutations (Fisher's Exact test, $p=0.0015$ ), whereas the association between FLT3-ITD and NPM1 mutations did not reach significance. Secondly, there was a negative association between NPM1 and myeloid transcription factor mutations (Fisher's Exact test, $p=0.0001$ ), and also between NPM1 and chromatin modifier mutations that occurred together only for two patients. Thirdly, all patients with TP53 mutations had high-risk cytogenetic abnormalities (Fisher's Exact test, $p<0.0001$ ). Fourthly, NPM1 mutations were associated with morphological signs 
of differentiation, i.e., FAB classification M2/M4/M5/M6 (Fisher's Exact test, $p=0.0233$ ). Finally, even in this relatively small patient cohort, we observed that no patients with TET2 mutations (13 patients) had IDH mutation (5 patients); this inverse correlation has been described in previous cohorts [6], but did not reach statistical significance in our smaller cohort. We did not detect any significant associations between individual mutation or mutational main classes and age, gender, or AML etiology (de novo/secondary). A trend toward higher number of identified mutations in patients $>65$ years was detected, (median 4 mutations $>65$ years, and median 3 mutations $<65$ years), although did not reach statistical significance in this patient cohort. To summarize, the frequencies of individual mutations and the various associations are similar to what has been described previously $[7,44]$; the observations thus suggest that our patient cohort of consecutive patients with relatively high peripheral blood blast counts is representative for AML in general.

\subsection{Expression of Molecular Differentiation Markers by Primary AML Cells: The Expression of the CD34 Stem Cell Markers Differs between Mutational Subsets}

The AML cell expression of eight common differentiation markers (CD13, CD14, CD15, CD33, CD34, CD45, CD117, and HLA-DR) was available for 62 unselected AML patients. We first did an unsupervised hierarchical cluster analysis based on this expression profile (Figure S2). We could then identify four main patient subsets, but no single mutation or mutational class showed significant associations with any of the four main patient clusters.

We investigated whether there were any significant correlations between the CD34 stem cell marker and any of the other differentiation markers, but no significant associations were then detected.

We finally investigated whether any of the mutations that are used as prognostic markers in routine clinical practice [2] showed significant correlations with the expression of single differentiation markers. These statistical analyses are summarized in Table S3. Firstly, NPM1 mutations showed a significant correlation with CD33 expression (Fisher's Exact test, $p=0.0107$ ) and a negative association with CD34 expression (Fisher's Exact test, $p<0.0001$ ). These NPM1 associations are similar to the observations in a previous large study of 184 unselected patients [45], and they are consistent with the observation that NPM1 mutations are frequently associated with morphological signs of differentiation (see above). Secondly, neither FLT3-ITD nor DNMT3A mutations showed any association with CD34 expression. NPM1 mutations are frequently combined with FLT3-ITD and DNA-methylation mutations [6], but only the negative NPM1 association reached significance in our relatively small cohort. Thirdly, patients with mutations in chromatin modifier genes showed an increased frequency of CD34 expression by their AML cells (Fisher's Exact test $p=0.0159$ ). We detected the combination of NPM1 and chromatin modifier mutations for only two patients, and this was similar to the observations in previous studies [7]. Thus, these mutational subsets also differ in their expression of differentiation markers, especially CD34 expression.

\subsection{AML Patients Can Be Subclassified Based on Their Constitutive Release of Extracellular Mediators, but this Capacity Shows no Association with the Mutational Profile}

Primary AML cells from 46 of the patients were available for additional studies of constitutive cytokine release during in vitro culture. This patient subset represents a constitutive and thereby unselected subset among the 71 patients included in our present study. We investigated the constitutive release of 34 soluble mediators, including several cytokines (interleukins, CCL and CXCL chemokines, immunoregulatory cytokines, growth factors), proteases, and protease regulators/inhibitors. A clustering analysis identified a subset of patients with generally high constitutive mediator release; the other patients showed generally low or intermediate release (Figure 2). Neither any single mutation nor mutational main class differed significantly when comparing the three patient subsets identified in this clustering analysis. 


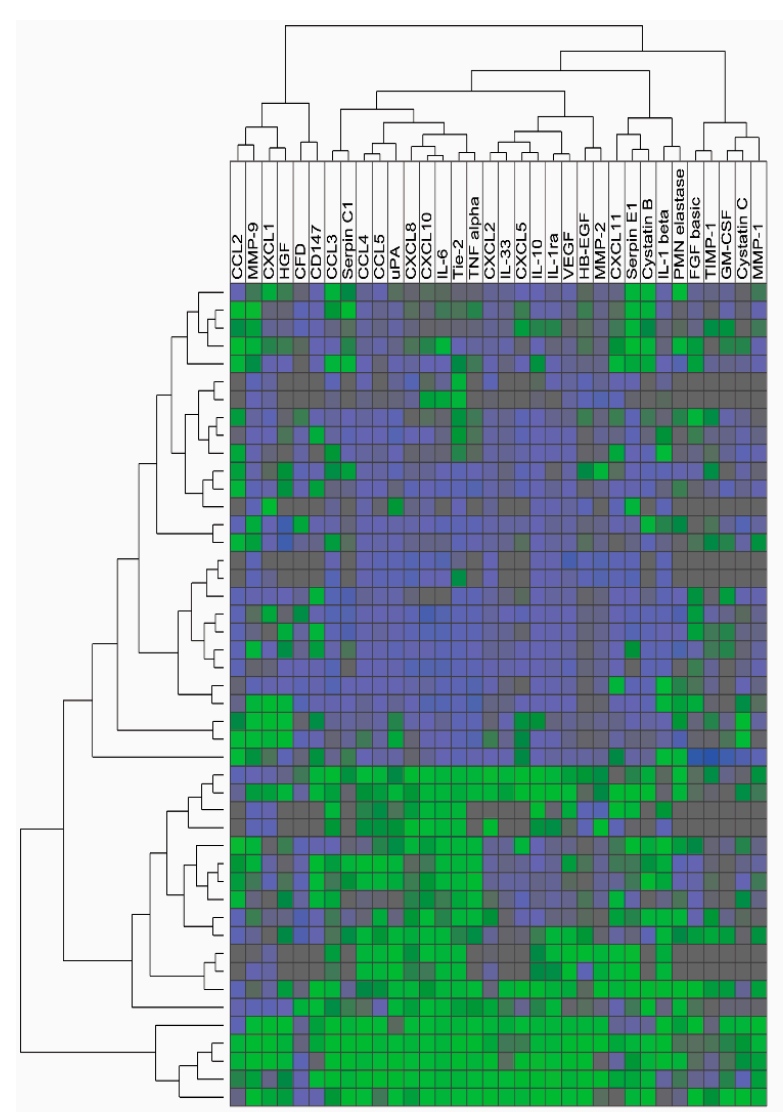

Distance metrics: Euclid
Linkage: COMPLETE

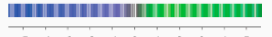
$54+3-2+1001223345$
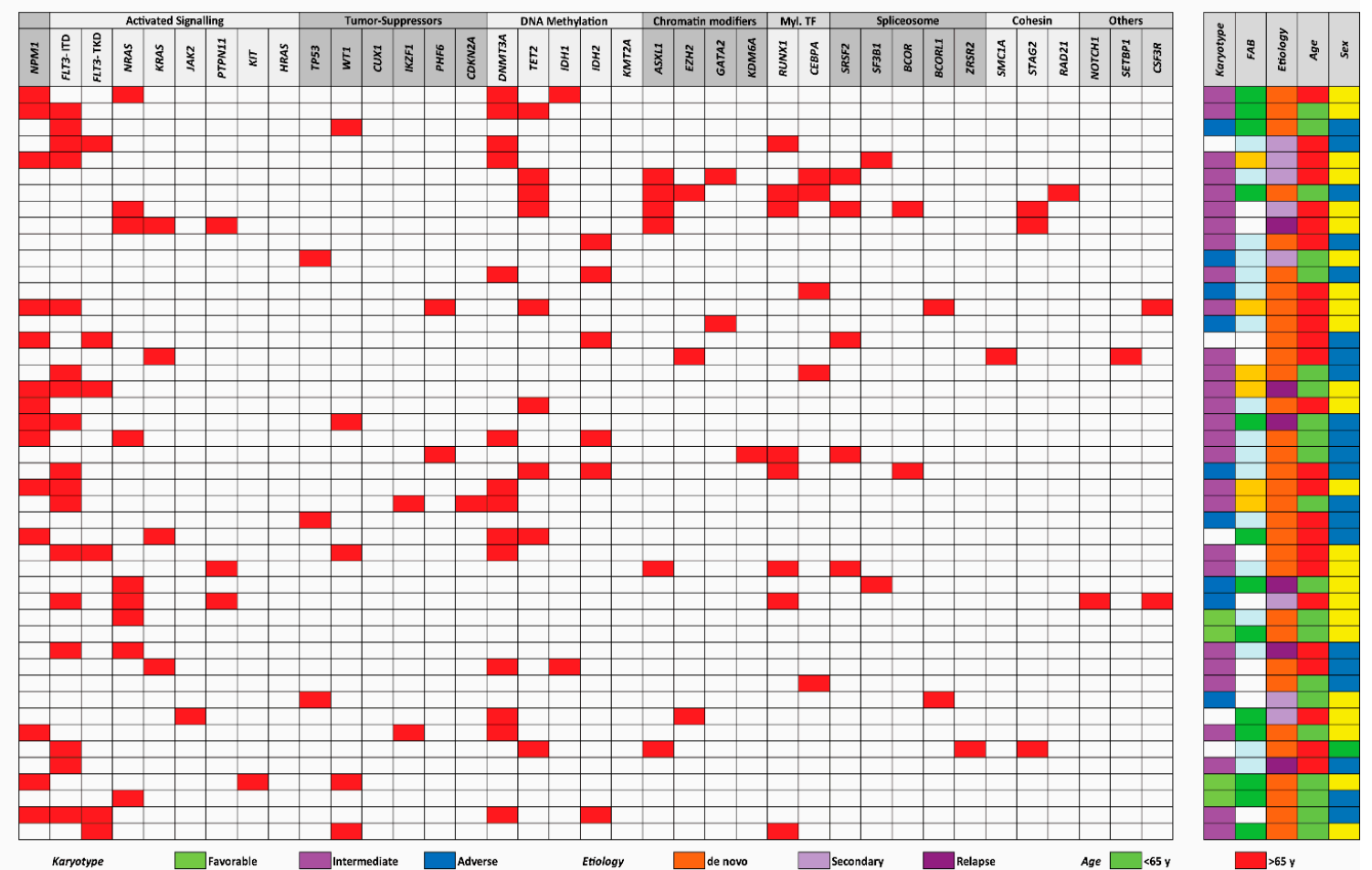

FAB

$\square \mathrm{Mo/m}$

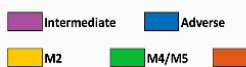

de novo

$\square$ Secondary

$C_{\text {Relapse }}$

${ }_{198} \square^{655 y}$

$\longrightarrow 65$

Figure 2. The secretome and genomic profile for 46 AML patients. Primary AML cells derived from a consecutive subset of 46 patients were cultured in vitro for $48 \mathrm{~h}$ and the supernatant levels of 34 soluble mediators were then determined. We performed an unsupervised hierarchical cluster analysis (Euclidean measure, and complete distance) based on these results and were then able to identify two distinct patient clusters corresponding to patients with generally high or intermediate/low supernatant level. 


\subsection{Comparison of Global Gene Expression Profiles for Patients with Generally High and Low Constitutive Release of Extracellular Mediators}

We have previously described differences in global gene expression profiles between AML cells with generally high and low constitutive mediator release [46]. We performed a similar comparison for the patients included in the present studies based on the differentially expressed genes, and we could then identify two main patient subsets based on this expression ( $\mathrm{d}$-score $>3.5 ; 149$ genes identified). However, these two subsets did not differ significantly with regard to the distribution of single mutations or the overall mutational profiles of the AML cell populations (Figure S3).

\subsection{Comparison of Proteomic Profiles for AML Cell Populations Showing Generally High and Low Constitutive Release of Extracellular Mediators}

Our proteomic analyses identified 5852 proteins, but 5586 proteins were left after leaving out protein contaminants, reverse hits, and proteins only identified by site. Our further analyses were based on 4350 proteins that could be detected in at least five patients for each of the two compared groups. A significant difference $(p<0.05)$ in protein abundance between the two groups was detected for 256 of these proteins (182 proteins increased in patients showing high constitutive release, 74 proteins being increased in the others), i.e., determined by Welch's $t$-test and Z-statistics (a list of selected proteins are described more in detail in Table S4 and the complete list of all 256 proteins is given in Table S5).

We first performed an unsupervised hierarchical cluster analysis (Euclidean measure, and complete distance) based on the 256 differentially expressed proteins (Figure 3). Our analysis identified two main clusters/subsets of patients corresponding to patients with generally high and low constitutive release by their AML cells; only one of the high release patients clustered as an outlier. Furthermore, we performed GO term overrepresentation analyses based on the 256 differentially abundant proteins. The analysis of those proteins showing increased expression $(n=74)$ in patients with low constitutive mediator release and returned significantly increased GO terms, which reflected an altered regulation of nuclear functions/transcription/RNA metabolism (Table 3 and Table S4). It can be seen that a major part of these genes are important for transcriptional regulation/RNA expression/RNA metabolism.

We then analyzed those proteins showing increased expression in AML cells with high constitutive cytokine release; the most significant GO-terms are listed in Table 4. When analyzing the proteins with regard to cell compartment the four largest terms (extracellular exosomes, cytosol, membrane, and cytoplasm) were only partly overlapping with regard to individual proteins and included 153 of the 182 proteins that were significantly increased in high-release AML cells (Figure 4). These four GO terms reflect cytoplasmic/cytosolic structures/functions together with the terms actin filament and phagocytic vesicle membrane. One of the terms reflects metabolic functions (NADPH oxidase complex), whereas the two last terms reflect cell surface functions/cellular communication (focal adhesion, membrane rafts). Analysis of biological processes and molecular functions included several relatively small GO terms that also reflect intracellular signaling, protein interactions, or cell surface receptor signaling (Table 4). Table S4 gives a more detailed description of those proteins that were identified both in the GO term analyses (Table 4, Figure 4) and in the network analysis (Figure 5; proteins in the large network to the left in the figure with increased levels in high-secreting cells).

The proteins with increased expression in patients with generally high constitutive release are presented in Figure 4 (all proteins included in the GO-terms GO:0070062-extracellular exosome, GO:0005829—cytosol, GO:0016020—membrane, or GO:0005737—cytoplasm); Table 3 (classification of proteins showing $p<0.01$ ); Table S4 (description of proteins from Table 3 with $p<0.01$ ); and Table S5 (the complete list of all 256 differentially expressed proteins). These more detailed analyses and classifications of individual proteins from Table 3 and Table S4 also show that AML cells showing generally high or low constitutive release of extracellular mediators differ especially with regard to transcriptional regulation, cell surface molecular profile, intracellular signaling, intracellular trafficking, and cell adhesion/migration. 

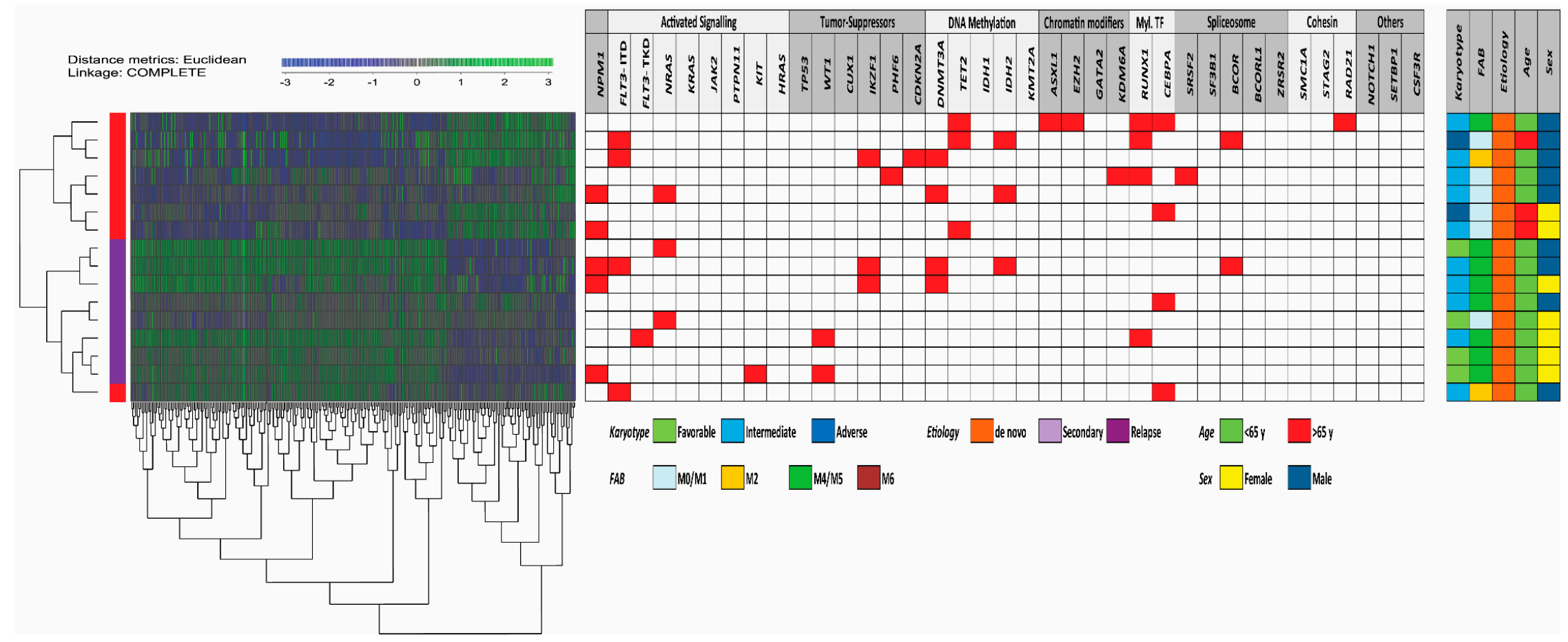

Figure 3. Identification of two main patient subsets based on proteomic differences of AML cells with high and low constitutive release. Eight of the 16 patients included in the proteomic studies belonged to the cluster characterized by generally high constitutive mediator release and the eight others showed low/intermediate secretion (Figure 2); 256 proteins differed significantly between these two groups. We performed an unsupervised hierarchical cluster analyses (Euclidean measure, and complete distance) based on the levels of these proteins, and the left part demonstrates the dendrogram and heat map; blue indicates low protein levels and green high levels. Two main clusters were then identified corresponding to the high and low/intermediate secretion patients except for one outlier patient (left column, red color indicating high release). As expected, the two main clusters were heterogeneous with regard to mutational frequencies (middle panel) and did not differ with regard to clinical or biological characteristics either (right panel). 
Table 3. Differentially expressed proteins in primary AML cell populations with high (left) and low (high) constitutive release of extracellular soluble mediators. The mediators are classified based on their main functional characteristics. The information is based on the Gene database and selected references from the PubMed database (Table S4). The proteins being increased in high-secreting AML cells are those proteins that were both included in the gene ontology (GO) terms GO:0070062—extracellular exosome, GO:0005829—cytosol, GO:0016020—membrane, and GO:0005737—cytoplasm (Figure 4), and also in the main interacting protein network in the left part of Figure 5 (Table S4). The proteins being increased in the low-secreting AML cells are those proteins included the GO terms GO:0000790—nuclear chromatin and GO:0005736—DNA-directed RNA polymerase I complex (Table 4).

\begin{tabular}{|c|c|c|}
\hline Main Classification & Increased Protein Levels in Cells with High Constitutive Release & $\begin{array}{l}\text { Increased Protein Levels in Cells with Low } \\
\text { Constitutive Release }\end{array}$ \\
\hline Nucleosome & & \multirow{5}{*}{$\begin{array}{c}\text { MBD3 } \\
\text { HIF0, HISTIH2AJ, MTA1, SMARCE1, MEN1, MBD3, } \\
\text { POLR1E, CLPX, POLR1A, POLR1B } \\
\text { CLPX, JUND, POG2 }\end{array}$} \\
\hline Chromatin, histone, transcription, RNA & TOLLIP, NFKB1 & \\
\hline DNA repair & & \\
\hline Oncogene & CBL, DBNL & \\
\hline Cell cycle regulation & IL16 & \\
\hline Intracellular signaling & $\begin{array}{l}\text { SYK, HCLS1, AKAP1, TLR2, TOLLIP, AGTRAP, ANXA2, CECR1, INPP5D, } \\
\text { LPKN, IKBKB, TBK1 }\end{array}$ & \\
\hline Tyrosine kinase & SYK, HCLS1, FGR, PKN1 & \\
\hline SRC tyrosine kinases & HCLS1, FGR, HCK, & \\
\hline PI3K-Akt-mTOR & NCF4 & \\
\hline RAC1 & $\begin{array}{l}\text { RAC1, NCF4, RHOT1, ARHGEF1, PKN1, RHOG, ARHGAP30, PREX1, } \\
\text { GMIP. DOK2, AKAP1 }\end{array}$ & \\
\hline GTPase & DNM2, ARHGEF1, PKN1, RHOG, ARHGAP30, PREX1, GMIP, AKAP1, & \\
\hline G-protein coupled receptors & ARRB2, ARHGEF1, PREX1, GRK6 & \\
\hline Phagocytosis & CYBA, NCF2, NCF4, ELMO2 & \\
\hline Protein degradation & CBL, SERPINA1 & \\
\hline Intracellular trafficking & VAMP3, DNM2, PICALM, SNX18, ARAP1, ARAP1, TOLLIP, AP1G2, & \\
\hline & S100A10, S100A4, TOM1, SDCDP, DNAJC13, EPN1, APHGAP, RAB27A & \\
\hline Microtubule, cytoskeleton, structure & DNM2, EPN1, SH3KBP1, PKN1, RHOG, AHNAK, SDCDP, S100A4, & \\
\hline Cell migration & $\begin{array}{c}\text { CKAP4, FAM49B } \\
\text { PLXNB2, HCK, DNM2, RHOG, ELMO2, AHNAK }\end{array}$ & \\
\hline Mitochondria, metabolism & FAM49B, FTL, IMPDH1, PDXK & CLPX \\
\hline Lysosomes & CTSH, CTSS, CTSZ, LYZ, PSAP & \\
\hline Cell metabolism, NADP & HCK, NCF4 & \\
\hline Cytokinesis & FMNL1 & \\
\hline Extracellular matrix, cell adhesion & EPN1, SH3KBP1 & \\
\hline Extracellular mediators & IL16, TLR2, TOLLIP & \\
\hline Cell surface molecules & ITGAL, ITGAM. ITGB2, SYK, LILRB2, PKN1, LPXN & \\
\hline Integrins & ITGAL, ITGAM. ITGB2, SYK, FGR, LPXN & \\
\hline Viability, apoptosis & SH3KBP1, PKN1, ARAP1, TLR2 & \\
\hline AML & CBL, PICALM & \\
\hline Differentiation & MNDA, NCF1, CECR1 & \\
\hline
\end{tabular}




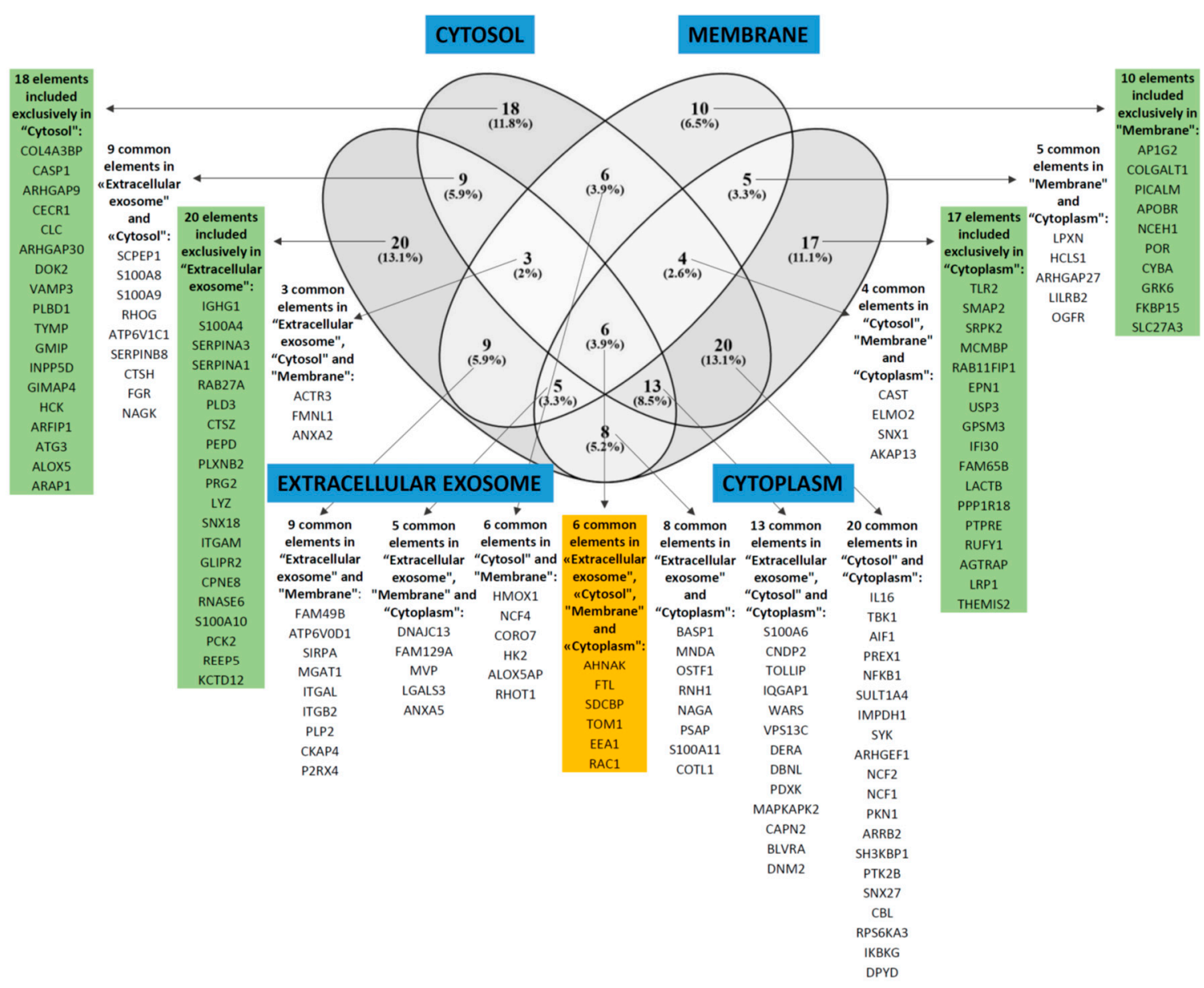

Figure 4. GO-terms including significantly increased proteins for AML cells with generally high constitutive release of extracellular soluble mediators. The over-representation analysis based on cellular compartment identified four GO terms with FDR $<0.05$ and including at least 40 proteins, i.e., GO:0070062—extracellular exosome, GO:0005829—cytosol, GO:0016020—membrane, and GO:0005737—cytoplasm. These four GO-terms were partly overlapping (only six proteins included in all four); together they included 153 of the 186 proteins that were increased in AML cells with generally high constitutive release compared with AML cells with low/intermediate constitutive release. 
Table 4. Significant GO-terms (i.e., FDR < 0.05) for proteins showing significantly increased levels in AML patients with intermediate/low and high constitutive mediator release.

\begin{tabular}{|c|c|c|c|c|}
\hline \multicolumn{2}{|c|}{ Low constitutive mediator release; list of significant GO-terms } & \multirow{2}{*}{$\frac{\text { Protein number }}{31}$} & \multirow{2}{*}{$\frac{\text { Fold enrichment }}{2.8}$} & \multirow{2}{*}{$\frac{\text { FDR }}{2.3 \times 10^{-5}}$} \\
\hline Cell compartment & GO:0005654—nucleoplasm & & & \\
\hline & GO:0000790—nuclear chromatin & 8 & 11 & 0.0099 \\
\hline & GO:0005736—DNA-directed RNA polymerase I complex & 4 & 80 & 0.017 \\
\hline Molecular function & GO:0003713—transcription coactivator activity & 9 & 8.5 & 0.011 \\
\hline & GO:0001054—RNA polymerase I activity & 4 & 78 & 0.018 \\
\hline \multicolumn{5}{|c|}{ High constitutive mediator release; list of significant GO-terms } \\
\hline \multirow[t]{7}{*}{ Biological processes } & GO:0006954—inflammatory response & 19 & 5.0 & $6.5 \times 10^{-5}$ \\
\hline & GO:0045087—innate immune response & 20 & 4.7 & $8.3 \times 10^{-5}$ \\
\hline & $\begin{array}{c}\text { GO:0048010 — vascular endothelial growth factor receptor } \\
\text { signaling pathway }\end{array}$ & 9 & 13 & $8.6 \times 10^{-4}$ \\
\hline & GO:0007229_integrin-mediated signaling pathway & 10 & 10 & $9.4 \times 10^{-4}$ \\
\hline & GO:0031623—receptor internalization & 7 & 16 & 0.0062 \\
\hline & GO:0007165—signal transduction & 29 & 2.5 & 0.015 \\
\hline & GO:0098609—cell-cell adhesion & 13 & 4.8 & 0.026 \\
\hline \multirow[t]{9}{*}{ Cell compartment } & GO:0070062—extracellular exosome & 73 & 2.7 & $1.4 \times 10^{-13}$ \\
\hline & GO:0005829—cytosol & 79 & 2.5 & $5.7 \times 10^{-13}$ \\
\hline & GO:0016020—membrane & 48 & 2.3 & $7.8 \times 10^{-5}$ \\
\hline & GO:0043020—NADPH oxidase complex & 5 & 43 & 0.0048 \\
\hline & GO:0005737—cytoplasm & 78 & 1.6 & 0.010 \\
\hline & GO:0030670—phagocytic vesicle membrane & 7 & 12 & 0.026 \\
\hline & GO:0005925_focal adhesion & 15 & 4.0 & 0.03 \\
\hline & GO:0045121-membrane raft & 11 & 5.6 & 0.038 \\
\hline & GO:0005884-actin filament & 7 & 11 & 0.046 \\
\hline \multirow[t]{3}{*}{ Molecular function } & GO:0005515-protein binding & 129 & 1.4 & $5.8 \times 10^{-6}$ \\
\hline & GO:0017124—SH3 domain binding & 11 & 8.9 & $5.8 \times 10^{-4}$ \\
\hline & GO:0035325-Toll-like receptor binding & 4 & 96 & 0.0058 \\
\hline
\end{tabular}




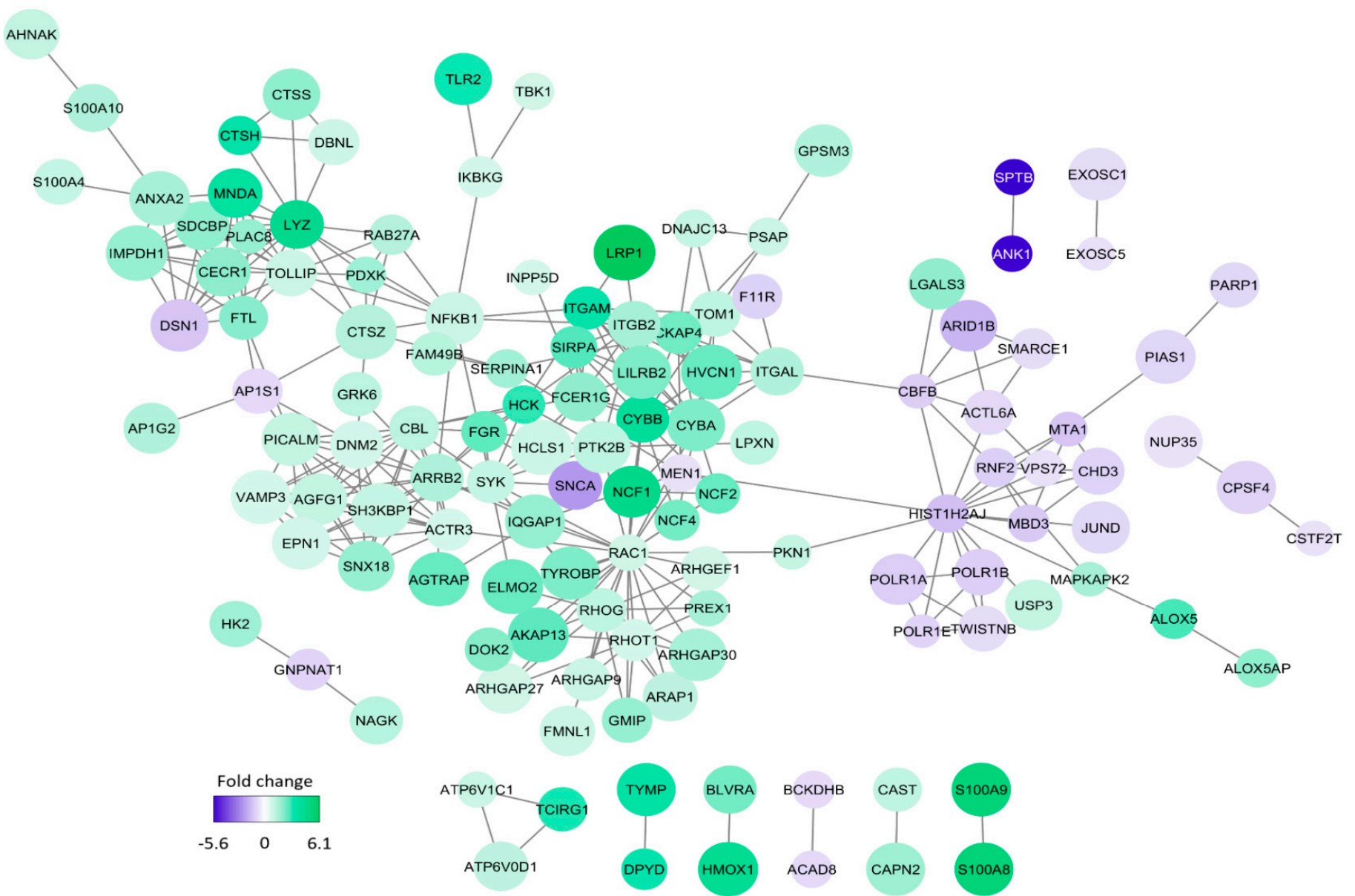

Figure 5. The network analysis of proteins showing differential expression in primary AML cells with generally high versus generally low constitutive release of extracellular mediators. The intensity of the color reflects the fold change (FC) significance when comparing the high- and low-release groups; thus a negative fold change indicates increased protein abundance in the low-release group (purple) and a positive fold change indicates increased protein abundance in the high-release group (green). This STRING-DB analysis was based only on the 256 proteins that were quantified and considered significantly different between the two groups; the figure thus shows proteins from our quantified data and no shells of interactors were considered. 
We finally did a molecular network analysis based on the 256 differentially abundant proteins, and Figure 5 shows all molecular connections identified in this analysis (those molecules without any connections are left out). A total of 129 proteins were included in various networks; most of them appeared in a large network linked to the nodes spleen tyrosine kinase (SYK), NCF4 (a cytosolic regulator of superoxide-producing NADPH-oxidase), ARRB2 (regulator of G-protein-coupled receptor activity), ACTR3 (a major constituent of the ARP2/3 complex located at the cell surface and being essential for cell motility), and RAC1 (a GTPase belonging to the RAS superfamily of small GTP-binding proteins). Our overrepresentation analysis showed that exosomal proteins as well as proteins important for intracellular trafficking were differentially expressed; both these groups are important for communication from the leukemic cells to neighboring AML supporting stromal cells [47]. On the other hand, our network analysis showed that these AML cells had increased levels of several members of a signaling pathway, including cell surface integrins $(\alpha \mathrm{L} \beta 2, \alpha \mathrm{M} \beta 2)$ known to mediate downstream signaling involving SYK and SRC kinase family members (FGR, HCK) [48-51]. Toll like receptor (TLR) 2 together with its downstream NFKB complex are also linked to this network [49]. Taken together these observations suggest that high constitutive extracellular release of soluble mediators is only a part of a more complex cellular phenotype that is characterized by differences in the bidirectional crosstalk between the leukemic cells and their neighboring AML-supporting cells. This bidirectional crosstalk involves cytokine-mediated signaling directed from the AML cells to the stromal cells. At the same time the stromal cells may influence the AML cells through soluble mediators or cell-cell contact with ligation of cell surface molecules, followed by downstream signaling (involving kinases and G-protein initiated signaling), and finally NFKB mediated modulation of cytokine/chemokine expression [48-52]. Finally, this crosstalk involves integrins that can mediate both inside-out and outside-in effects [48].

\section{Discussion}

AML is a heterogeneous disease, and this can also be seen from our present studies of primary human AML cells derived from a cohort of consecutive patients. In this study we focused on the molecular genetic abnormalities and the proteomic profiles of the leukemic cells [53]. Both the number and the nature of the molecular genetic abnormalities differed between the patients (number of detected mutations per patients $0-7$, median 3.5 mutations). The frequencies of the various mutations were comparable to previous studies [6,7], NPM1 mutations were associated with molecular and morphological signs of differentiation [45], and TP53 mutations were associated with adverse karyotypes [54]. Taken together, these observations suggest that we investigated a representative AML patient population, even though we selected patients with relatively high peripheral blood blast counts/percentages.

In the present study, we included a group of consecutive and thereby unselected AML patients with a high percentage of leukemic blasts in peripheral blood. We used this selection of patients so that highly enriched AML cell populations could be prepared by density gradient separation alone; the risk of inducing molecular and/or functional alterations in the AML patients by more extensive cell separation procedures was thereby avoided [55]. Our results may therefore be representative only for this selected subset of patients, but several observations suggest that they possibly are representative for AML in general. Firstly, our patients showed an expected fraction of secondary versus de novo AML $[56,57]$. Secondly, as previously described in detail patients selected according to these criteria show a similar distribution of cytogenetic abnormalities as AML patients in general [30]. Thirdly, our present study shows that the distribution of various molecular genetic abnormalities is also similar to AML in general $[6,7,44,58]$. Finally, we have described in detail the selection of the 16 AML patients included in our proteomic studies (see Section 3.5), and they should then be regarded as representative for relatively young AML patients.

Extensive separation procedures will influence the functional characteristics of primary human AML cells, and one would expect that in vitro incubation in culture medium would have similar effects. However, previous studies have shown that the characteristics of even long-term cultured primary 
human AML cells are associated with patient survival [59], an observation suggesting that even in vitro cultured cells will reflect functional characteristics of clinical relevance.

Distinct immunophenotype profiles may be associated with specific mutations, and search for immunophenotype-based screening approaches have therefore been suggested $[60,61]$. We investigated the immunophenotype profiles of individual patients based on the expression of eight differentiation markers commonly used for classification of myeloid cells. We identified four different main clusters/patient subsets based on this profiling, but no single mutation or mutation main classes showed significant associations to any of these profiles. However, associations between mutations and single differentiation markers were observed, especially expression of the CD34 stem cell marker that was negatively associated with NPM1 mutations as well as FLT3-ITD and DNMT3 mutations, whereas chromatin modifier mutations were positively associated with CD34 expression. Such associations have also been described previously [45,62]. A possible explanation for this is that single mutations may have a major impact on the expression of single or related markers, whereas the overall mutational profile has a major impact on the overall differentiation profile.

In previous studies we showed that the constitutive release of a wide range of soluble mediators by primary AML cells varied considerably between patients, and a subset of patients then showed a generally high release compared with other patients that either showed intermediate or low release $[11,52]$. This capacity of constitutive mediator release was tested in a highly standardized in vitro model. We investigated the constitutive release for a consecutive subset of our patients, and again we found that a subset of patients showed generally higher release of most mediators compared with the other patients. We then selected those samples that were derived before the first time of diagnosis for all relatively young patients that completed intensive chemotherapy. We compared the proteomic profiles of the primary AML cells for eight patients showing high and another group of eight patients showing generally lower mediator release.

Several proteins were differentially expressed when comparing patients with generally high and low constitutive cytokine release. The high release patients showed high expression, especially of proteins involved in intracellular signaling, intracellular transport/trafficking and communication between cells (soluble mediators, exosomes, cell surface molecules, and intracellular mediators downstream to cell surface receptors). We did not identify any of the soluble mediators when analyzing differentially abundant cell proteins between the two patient subsets; this is not unexpected because there is often not a strong correlation between cellular levels and extracellular release of soluble mediators during culture [34].

The high constitutive mediator release should in our opinion be regarded as only a part of a more complex communication phenotype with neighboring non-leukemic stromal cells. In contrast, the cell populations with low constitutive release showed increased abundance proteins involved in or regulating gene transcription/RNA synthesis/RNA metabolism. A possible hypothesis may be that cells with high constitutive release have a higher dependency on neighboring AML-supporting stromal cells than leukemia cells showing low constitutive release. We would emphasize that primary AML cells have a wide range of secreted biomolecules, which can be useful in classification/prognostication and as therapeutic targets $[11,52,63]$. The mediators included in the present study are well-characterized and are released at detectable levels for most patients. For these reasons they should be regarded as biologically important in the disease, but they probably represent only a part of the AML cell secretome that is involved in the bidirectional crosstalk between leukemic and non-leukemic cells in their common bone marrow microenvironment.

\section{Conclusions}

We conclude that the high constitutive extracellular release of soluble mediators by primary human AML cells seems to reflect a complex functional phenotype with regard to communication between AML cells and their neighboring non-leukemic stromal cells in their common bone marrow microenvironment. Our proteomic comparison has identified high expression in this patient subset of 
several intracellular molecules that are regarded as possible therapeutic targets in human AML. Dual targeting of intracellular signaling and extracellular communication should therefore be considered for these patients.

Supplementary Materials: The following are available online at http://www.mdpi.com/2077-0383/8/7/970/s1, Figure S1: Mutation profile and mutation classes. Figure S2: The immunophenotypic profile and mutation profile. Figure S3: Transcriptomics data based on AML secretomic profile. Table S1: The biological and clinical characteristics of patients in the proteomic studies. Table S2: The mutational distribution for patients included in the proteomic studies. Table S3: Statistical comparisons of associations between various mutations and between mutations and signs of AML cell differentiation (morphology, CD34 expression). Table S4: Proteomic profiling based on AML secretome. Table S5: All proteins differently expressed between high and low secretome group.

Author Contributions: Conceptualization, H.R. and Ø.B.; methodology, H.R., E.A., A.K.B., S.B.B., I.S.G., R.B.F., and R.H.; software, H.R., E.A., and A.K.B.; validation, H.R. and Ø.B.; formal analysis, H.R., E.A., and A.K.B.; investigation, H.R., E.A., A.K.B., S.B.B., I.S.G., R.B.F., R.H., and Ø.B.; resources, H.R. and Ø.B.; data curation, H.R., E.A., and A.K.B.; writing - original draft preparation, H.R. and Ø.B.; writing-review and editing, H.R., E.A., A.K.B., S.B.B., I.S.G., R.B.F., R.H., and Ø.B; visualization, H.R., E.A., and A.K.B.; supervision, Ø.B.; project administration, H.R., and Ø.B.; funding acquisition, Ø.B.

Funding: This research was funded by The Norwegian Cancer Society (DNK 100933) and Helse-Vest.

Acknowledgments: Technical support from Karen Marie Hagen and Kristin Paulsen Rye is greatly appreciated.

Conflicts of Interest: The authors declare no conflict of interest.

\section{References}

1. Döhner, H.; Weisdorf, D.J.; Bloomfield, C.D. Acute myeloid leukemia. N. Engl. J. Med. 2015, 373, 1136-1152. [PubMed]

2. Döhner, H.; Estey, E.; Grimwade, D.; Amadori, S.; Appelbaum, F.R.; Buchner, T.; Dombret, H.; Ebert, B.L.; Fenaux, P.; Larson, R.A.; et al. Diagnosis and management of aml in adults: 2017 eln recommendations from an international expert panel. Blood 2017, 129, 424-447. [PubMed]

3. Arber, D.A.; Orazi, A.; Hasserjian, R.; Thiele, J.; Borowitz, M.J.; Le Beau, M.M.; Bloomfield, C.D.; Cazzola, M.; Vardiman, J.W. The 2016 revision to the world health organization classification of myeloid neoplasms and acute leukemia. Blood 2016, 127, 2391-2405. [PubMed]

4. Schlenk, R.F.; Dohner, K.; Krauter, J.; Frohling, S.; Corbacioglu, A.; Bullinger, L.; Habdank, M.; Spath, D.; Morgan, M.; Benner, A.; et al. Mutations and treatment outcome in cytogenetically normal acute myeloid leukemia. N. Engl. J. Med. 2008, 358, 1909-1918. [PubMed]

5. Valk, P.J.; Verhaak, R.G.; Beijen, M.A.; Erpelinck, C.A.; Barjesteh van Waalwijk van Doorn-Khosrovani, S.; Boer, J.M.; Beverloo, H.B.; Moorhouse, M.J.; van der Spek, P.J.; Lowenberg, B.; et al. Prognostically useful gene-expression profiles in acute myeloid leukemia. N. Engl. J. Med. 2004, 350, 1617-1628. [PubMed]

6. Papaemmanuil, E.; Gerstung, M.; Bullinger, L.; Gaidzik, V.I.; Paschka, P.; Roberts, N.D.; Potter, N.E.; Heuser, M.; Thol, F.; Bolli, N.; et al. Genomic classification and prognosis in acute myeloid leukemia. N. Engl. J. Med. 2016, 374, 2209-2221. [PubMed]

7. Cancer Genome Atlas Research, N.; Ley, T.J.; Miller, C.; Ding, L.; Raphael, B.J; Mungall, A.J.; Robertson, A.; Hoadley, K.; Triche, T.J., Jr.; Laird, P.W.; et al. Genomic and epigenomic landscapes of adult de novo acute myeloid leukemia. N. Engl. J. Med. 2013, 368, 2059-2074.

8. $\quad$ Eppert, K.; Takenaka, K.; Lechman, E.R.; Waldron, L.; Nilsson, B.; van Galen, P.; Metzeler, K.H.; Poeppl, A.; Ling, V.; Beyene, J.; et al. Stem cell gene expression programs influence clinical outcome in human leukemia. Nat. Med. 2011, 17, 1086-1093.

9. Brenner, A.K.; Reikvam, H.; Lavecchia, A.; Bruserud, O. Therapeutic targeting the cell division cycle 25 (cdc25) phosphatases in human acute myeloid leukemia-the possibility to target several kinases through inhibition of the various cdc25 isoforms. Molecules 2014, 19, 18414-18447.

10. Hatfield, K.J.; Reikvam, H.; Bruserud, O. Identification of a subset of patients with acute myeloid leukemia characterized by long-term in vitro proliferation and altered cell cycle regulation of the leukemic cells. Expert. Opin. Therap. Targets 2014, 18, 1237-1251. 
11. Brenner, A.K.; Reikvam, H.; Bruserud, O. A subset of patients with acute myeloid leukemia has leukemia cells characterized by chemokine responsiveness and altered expression of transcriptional as well as angiogenic regulators. Front Immunol. 2016, 7, 205. [PubMed]

12. Griessinger, E.; Anjos-Afonso, F.; Vargaftig, J.; Taussig, D.C.; Lassailly, F.; Prebet, T.; Imbert, V.; Nebout, M.; Vey, N.; Chabannon, C.; et al. Frequency and dynamics of leukemia-initiating cells during short-term ex vivo culture informs outcomes in acute myeloid leukemia patients. Cancer Res. 2016, 76, 2082-2086. [PubMed]

13. Griessinger, E.; Anjos-Afonso, F.; Pizzitola, I.; Rouault-Pierre, K.; Vargaftig, J.; Taussig, D.; Gribben, J.; Lassailly, F.; Bonnet, D. A niche-like culture system allowing the maintenance of primary human acute myeloid leukemia-initiating cells: A new tool to decipher their chemoresistance and self-renewal mechanisms. Stem Cells Transl. Med. 2014, 3, 520-529. [PubMed]

14. Hauge, M.; Bruserud, O.; Hatfield, K.J. Targeting of cell metabolism in human acute myeloid leukemia-more than targeting of isocitrate dehydrogenase mutations and pi3k/akt/mtor signaling? Eur. J. Haematol. 2016, 96, $211-221$. [PubMed]

15. Hernandez-Valladares, M.; Aasebo, E.; Mjaavatten, O.; Vaudel, M.; Bruserud, O.; Berven, F.; Selheim, F. Reliable fasp-based procedures for optimal quantitative proteomic and phosphoproteomic analysis on samples from acute myeloid leukemia patients. Biol. Proced. Online 2016, 18, 13. [PubMed]

16. Aasebo, E.; Mjaavatten, O.; Vaudel, M.; Farag, Y.; Selheim, F.; Berven, F.; Bruserud, O.; Hernandez-Valladares, M. Freezing effects on the acute myeloid leukemia cell proteome and phosphoproteome revealed using optimal quantitative workflows. J. Proteomics 2016, 145, 214-225. [PubMed]

17. Aasebo, E.; Vaudel, M.; Mjaavatten, O.; Gausdal, G.; Van der Burgh, A.; Gjertsen, B.T.; Doskeland, S.O.; Bruserud, O.; Berven, F.S.; Selheim, F. Performance of super-silac based quantitative proteomics for comparison of different acute myeloid leukemia (aml) cell lines. Proteomics 2014, 14, 1971-1976. [PubMed]

18. Ossenkoppele, G.J.; Janssen, J.J.; van de Loosdrecht, A.A. Risk factors for relapse after allogeneic transplantation in acute myeloid leukemia. Haematologica 2016, 101, 20-25. [PubMed]

19. Terwijn, M.; Zeijlemaker, W.; Kelder, A.; Rutten, A.P.; Snel, A.N.; Scholten, W.J.; Pabst, T.; Verhoef, G.; Lowenberg, B.; Zweegman, S.; et al. Leukemic stem cell frequency: A strong biomarker for clinical outcome in acute myeloid leukemia. PloS ONE 2014, 9, e107587.

20. Wouters, R.; Cucchi, D.; Kaspers, G.J.; Schuurhuis, G.J.; Cloos, J. Relevance of leukemic stem cells in acute myeloid leukemia: Heterogeneity and influence on disease monitoring, prognosis and treatment design. Expert. Rev. Hematol. 2014, 7, 791-805.

21. Majeti, R. Clonal evolution of pre-leukemic hematopoietic stem cells precedes human acute myeloid leukemia. Best Pract. Res. Clin. Haematol. 2014, 27, 229-234.

22. Stapnes, C.; Gjertsen, B.T.; Reikvam, H.; Bruserud, O. Targeted therapy in acute myeloid leukaemia: Current status and future directions. Expert. Opin. Investig. Drugs 2009, 18, 433-455. [PubMed]

23. Binder, S.; Luciano, M.; Horejs-Hoeck, J. The cytokine network in acute myeloid leukemia (aml): A focus on pro- and anti-inflammatory mediators. Cytokine Growth Factor Rev. 2018, 43, 8-15. [PubMed]

24. Brenner, A.K.; Andersson Tvedt, T.H.; Bruserud, O. The complexity of targeting pi3k-akt-mtor signalling in human acute myeloid leukaemia: The importance of leukemic cell heterogeneity, neighbouring mesenchymal stem cells and immunocompetent cells. Molecules 2016, 21.

25. Reikvam, H.; Hatfield, K.J.; Fredly, H.; Nepstad, I.; Mosevoll, K.A.; Bruserud, O. The angioregulatory cytokine network in human acute myeloid leukemia-from leukemogenesis via remission induction to stem cell transplantation. Eur. Cytokine Netw. 2012, 23, 140-153. [PubMed]

26. Kupsa, T.; Horacek, J.M.; Jebavy, L. The role of cytokines in acute myeloid leukemia: A systematic review. Biomed. Pap. Med. Fac. Univ. Palacky Olomouc Czech Repub. 2012, 156, 291-301. [PubMed]

27. Cho, B.S.; Kim, H.J.; Konopleva, M. Targeting the cxcl12/cxcr4 axis in acute myeloid leukemia: From bench to bedside. Korean J. Intern. Med. 2017, 32, 248-257. [PubMed]

28. Bernasconi, P.; Farina, M.; Boni, M.; Dambruoso, I.; Calvello, C. Therapeutically targeting self-reinforcing leukemic niches in acute myeloid leukemia: A worthy endeavor? Am. J. Hematol. 2016, 91, 507-517. [PubMed]

29. Brenner, A.K.; Tvedt, T.H.; Nepstad, I.; Rye, K.P.; Hagen, K.M.; Reikvam, H.; Bruserud, O. Patients with acute myeloid leukemia can be subclassified based on the constitutive cytokine release of the leukemic cells; the possible clinical relevance and the importance of cellular iron metabolism. Expert. Opin. Therap. Targets 2017, 21, 357-369. 
30. Bruserud, O.; Hovland, R.; Wergeland, L.; Huang, T.S.; Gjertsen, B.T. Flt3-mediated signaling in human acute myelogenous leukemia (aml) blasts: A functional characterization of flt3-ligand effects in aml cell populations with and without genetic flt3 abnormalities. Haematologica 2003, 88, 416-428.

31. Reikvam, H.; Hovland, R.; Forthun, R.B.; Erdal, S.; Gjertsen, B.T.; Fredly, H.; Bruserud, O. Disease-stabilizing treatment based on all-trans retinoic acid and valproic acid in acute myeloid leukemia-identification of responders by gene expression profiling of pretreatment leukemic cells. BMC Cancer 2017, 17, 630.

32. Staffas, A.; Kanduri, M.; Hovland, R.; Rosenquist, R.; Ommen, H.B.; Abrahamsson, J.; Forestier, E.; Jahnukainen, K.; Jonsson, O.G.; Zeller, B.; et al. Presence of flt3-itd and high baalc expression are independent prognostic markers in childhood acute myeloid leukemia. Blood 2011, 118, 5905-5913. [PubMed]

33. Wangen, R.; Aasebo, E.; Trentani, A.; Doskeland, S.O.; Bruserud, O.; Selheim, F.; Hernandez-Valladares, M. Preservation method and phosphate buffered saline washing affect the acute myeloid leukemia proteome. Int. J. Mol. Sci. 2018, 19, 296.

34. Aasebo, E.; Hernandez-Valladares, M.; Selheim, F.; Berven, F.S.; Brenner, A.K.; Bruserud, O. Proteomic profiling of primary human acute myeloid leukemia cells does not reflect their constitutive release of soluble mediators. Proteomes 2018, 7, 1.

35. Cox, J.; Mann, M. Maxquant enables high peptide identification rates, individualized p.P.B.-range mass accuracies and proteome-wide protein quantification. Nat. Biotechnol. 2008, 26, 1367-1372. [PubMed]

36. Cox, J.; Matic, I.; Hilger, M.; Nagaraj, N.; Selbach, M.; Olsen, J.V.; Mann, M. A practical guide to the maxquant computational platform for silac-based quantitative proteomics. Nat. Protoc. 2009, 4, 698-705. [PubMed]

37. Stavrum, A.K.; Petersen, K.; Jonassen, I.; Dysvik, B. Analysis of gene-expression data using j-express. Curr. Protoc. Bioinformat. 2008, Chapter 7, Unit 7.3. [CrossRef]

38. Mi, H.; Muruganujan, A.; Casagrande, J.T.; Thomas, P.D. Large-scale gene function analysis with the panther classification system. Nat. Protocols 2013, 8, 1551. [PubMed]

39. Tyanova, S.; Temu, T.; Sinitcyn, P.; Carlson, A.; Hein, M.Y.; Geiger, T.; Mann, M.; Cox, J. The perseus computational platform for comprehensive analysis of (prote)omics data. Nat. Methods 2016, 13, 731-740.

40. Arntzen, M.O.; Koehler, C.J.; Barsnes, H.; Berven, F.S.; Treumann, A.; Thiede, B. Isobariq: Software for isobaric quantitative proteomics using iptl, itraq, and tmt. J. Proteome Res. 2011, 10, 913-920.

41. Huang, D.W.; Sherman, B.T.; Tan, Q.; Collins, J.R.; Alvord, W.G.; Roayaei, J.; Stephens, R.; Baseler, M.W.; Lane, H.C.; Lempicki, R.A. The david gene functional classification tool: A novel biological module-centric algorithm to functionally analyze large gene lists. Genome Biol. 2007, 8, R183. [CrossRef] [PubMed]

42. Szklarczyk, D.; Morris, J.H.; Cook, H.; Kuhn, M.; Wyder, S.; Simonovic, M.; Santos, A.; Doncheva, N.T.; Roth, A.; Bork, P.; et al. The string database in 2017: Quality-controlled protein-protein association networks, made broadly accessible. Nucleic Acids Res. 2017, 45, D362-D368. [CrossRef] [PubMed]

43. Shannon, P.; Markiel, A.; Ozier, O.; Baliga, N.S.; Wang, J.T.; Ramage, D.; Amin, N.; Schwikowski, B.; Ideker, T. Cytoscape: A software environment for integrated models of biomolecular interaction networks. Genome Res. 2003, 13, 2498-2504. [CrossRef] [PubMed]

44. Patel, J.L.; Schumacher, J.A.; Frizzell, K.; Sorrells, S.; Shen, W.; Clayton, A.; Jattani, R.; Kelley, T.W. Coexisting and cooperating mutations in npm1-mutated acute myeloid leukemia. Leukemia Res 2017, 56, 7-12. [CrossRef] [PubMed]

45. Tsykunova, G.; Reikvam, H.; Hovland, R.; Bruserud, O. The surface molecule signature of primary human acute myeloid leukemia (aml) cells is highly associated with npm1 mutation status. Leukemia 2012, 26, 557-559. [CrossRef] [PubMed]

46. Honnemyr, M.; Bruserud, O.; Brenner, A.K. The constitutive protease release by primary human acute myeloid leukemia cells. J. Cancer Res. Clin. Oncol. 2017, 143, 1985-1998. [CrossRef]

47. Brenner, A.K.; Nepstad, I.; Bruserud, O. Mesenchymal stem cells support survival and proliferation of primary human acute myeloid leukemia cells through heterogeneous molecular mechanisms. Front Immunol. 2017, 8, 106. [CrossRef]

48. Johansen, S.; Brenner, A.K.; Bartaula-Brevik, S.; Reikvam, H.; Bruserud, O. The possible importance of beta3 integrins for leukemogenesis and chemoresistance in acute myeloid leukemia. Int. J. Mol. Sci. 2018, 19, 251. [CrossRef]

49. Reikvam, H.; Olsnes, A.M.; Gjertsen, B.T.; Ersvar, E.; Bruserud, O. Nuclear factor-kappab signaling: A contributor in leukemogenesis and a target for pharmacological intervention in human acute myelogenous leukemia. Crit. Rev. Oncog. 2009, 15, 1-41. [CrossRef] 
50. Schmitt, A.; Li, L.; Giannopoulos, K.; Greiner, J.; Reinhardt, P.; Wiesneth, M.; Schmitt, M. Quantitative expression of toll-like receptor-2, -4 , and -9 in dendritic cells generated from blasts of patients with acute myeloid leukemia. Transfusion 2008, 48, 861-870. [CrossRef]

51. Bartaula-Brevik, S.; Lindstad Brattas, M.K.; Tvedt, T.H.A.; Reikvam, H.; Bruserud, O. Splenic tyrosine kinase (syk) inhibitors and their possible use in acute myeloid leukemia. Expert Opin. Investig. Drugs 2018, 27, 377-387. [CrossRef] [PubMed]

52. Bruserud, O.; Ryningen, A.; Olsnes, A.M.; Stordrange, L.; Oyan, A.M.; Kalland, K.H.; Gjertsen, B.T. Subclassification of patients with acute myelogenous leukemia based on chemokine responsiveness and constitutive chemokine release by their leukemic cells. Haematologica 2007, 92, 332-341. [CrossRef] [PubMed]

53. Godley, L.A. Profiles in leukemia. N. Engl. J. Med 2012, 366, 1152-1153. [CrossRef] [PubMed]

54. Rucker, F.G.; Schlenk, R.F.; Bullinger, L.; Kayser, S.; Teleanu, V.; Kett, H.; Habdank, M.; Kugler, C.M.; Holzmann, K.; Gaidzik, V.I.; et al. Tp53 alterations in acute myeloid leukemia with complex karyotype correlate with specific copy number alterations, monosomal karyotype, and dismal outcome. Blood 2012, 119, 2114-2121. [CrossRef] [PubMed]

55. Granfeldt Ostgard, L.S.; Medeiros, B.C.; Sengelov, H.; Norgaard, M.; Andersen, M.K.; Dufva, I.H.; Friis, L.S.; Kjeldsen, E.; Marcher, C.W.; Preiss, B.; et al. Epidemiology and clinical significance of secondary and therapy-related acute myeloid leukemia: A national population-based cohort study. J. Clin. Oncol. 2015, 33, 3641-3649. [CrossRef] [PubMed]

56. Bruserud, O.; Gjertsen, B.T.; Foss, B.; Huang, T.S. New strategies in the treatment of acute myelogenous leukemia (aml): In vitro culture of aml cells-the present use in experimental studies and the possible importance for future therapeutic approaches. Stem Cells 2001, 19, 1-11. [CrossRef] [PubMed]

57. Bruserud, O.; Gjertsen, B.T.; von Volkman, H.L. In vitro culture of human acute myelogenous leukemia (aml) cells in serum-free media: Studies of native aml blasts and aml cell lines. J. Hematother. Stem Cell Res. 2000, 9, $923-932$. [CrossRef]

58. Patel, J.P.; Gonen, M.; Figueroa, M.E.; Fernandez, H.; Sun, Z.; Racevskis, J.; Van Vlierberghe, P.; Dolgalev, I.; Thomas, S.; Aminova, O.; et al. Prognostic relevance of integrated genetic profiling in acute myeloid leukemia. N. Engl. J. Med. 2012, 366, 1079-1089. [CrossRef]

59. Brenner, A.K.; Aasebo, E.; Hernandez-Valladares, M.; Selheim, F.; Berven, F.; Gronningsaeter, I.S.; Bartaula-Brevik, S.; Bruserud, O. The capacity of long-term in vitro proliferation of acute myeloid leukemia cells supported only by exogenous cytokines is associated with a patient subset with adverse outcome. Cancers 2019, 11, 73. [CrossRef]

60. Angelini, D.F.; Ottone, T.; Guerrera, G.; Lavorgna, S.; Cittadini, M.; Buccisano, F.; De Bardi, M.; Gargano, F.; Maurillo, L.; Divona, M.; et al. A leukemia-associated cd34/cd123/cd25/cd99+ immunophenotype identifies flt3-mutated clones in acute myeloid leukemia. Clin. Cancer Res. 2015, 21, 3977-3985. [CrossRef]

61. Mannelli, F.; Ponziani, V.; Bencini, S.; Bonetti, M.I.; Benelli, M.; Cutini, I.; Gianfaldoni, G.; Scappini, B.; Pancani, F.; Piccini, M.; et al. Cebpa-double-mutated acute myeloid leukemia displays a unique phenotypic profile: A reliable screening method and insight into biological features. Haematologica 2017, 102, 529-540. [CrossRef] [PubMed]

62. Falini, B.; Mecucci, C.; Tiacci, E.; Alcalay, M.; Rosati, R.; Pasqualucci, L.; La Starza, R.; Diverio, D.; Colombo, E.; Santucci, A.; et al. Cytoplasmic nucleophosmin in acute myelogenous leukemia with a normal karyotype. $N$. Engl. J. Med. 2005, 352, 254-266. [CrossRef] [PubMed]

63. Reikvam, H.; Fredly, H.; Kittang, A.O.; Bruserud, O. The possible diagnostic and prognostic use of systemic chemokine profiles in clinical medicine;the experience in acute myeloid leukemia from disease development and diagnosis via conventional chemotherapy to allogeneic stem cell transplantation. Toxins 2013, 5, 336-362. [CrossRef] [PubMed]

(C) 2019 by the authors. Licensee MDPI, Basel, Switzerland. This article is an open access article distributed under the terms and conditions of the Creative Commons Attribution (CC BY) license (http://creativecommons.org/licenses/by/4.0/). 